\title{
The Impact of the Coronavirus Disease-19 Pandemic on Sexual Behavior of Marriage People in Indonesia
}

\author{
Jefry Albari Tribowo ${ }^{1} \mathbb{D}$, Tjahjo Djojo Tanojo ${ }^{1}$, Supardi Supardi ${ }^{1}$, Cennikon Pakpahan ${ }^{1,2}$ (D), Eko Budi Siswidiyanto ${ }^{1}$, \\ Andri Rezano ${ }^{1,3} \mathbb{D}$, Reny l'tishom ${ }^{2 *}$ iD \\ ${ }^{1}$ Andrology Specialist Program, Faculty of Medicine, Universitas Airlangga, Dr. Soetomo General Hospital Surabaya, Indonesia; \\ ${ }^{2}$ Department of Biomedical Sciences, Faculty of Medicine, Universitas Airlangga, Surabaya, Indonesia; ${ }^{3}$ Department of \\ Biomedical Sciences, Faculty of Medicine, Universitas Padjadjaran, Sumedang, Indonesia
}

Edited by: Slavica Hristomanova-Mitkovsk itation: Tribowo JA, Tanojo TD, Supardi S, Pakpahan C, Siswidiyanto EB, Rezano A, I'tishom R. The Impact of the Marriage People in Indonesia Open Access Maced J Med Sci. 2021 Jun 23; $9(A): 440-445$ https://doi.org/10.3889/oamjms.2021.627 Keywords: Coronavirus; Marriage stability; Pandemic Sexual relationship; Social restriction ${ }^{*}$ Correspondence: Reny l'tishom, Department of
Biomedical Sciences, Faculty of Medicine, Universitas Airlangga, Surabaya 60826, Indonesia. -mail: ritishom@fk.unair.ac.id Revised: 08-Jun-202 Accepted: $13-J u n-2021$ Copyright: ๑ 2021 Jefry Albari Tribowo, Tjahjo Djojo Tanojo, Supardi Supardi, Cennikon Pakpahan, Eko Budi Siswidiyanto, Andri Rezano, Reny I'tishom Funding: This research did not receive any financial Competing Interests: The authors have declared that no competing interests exis Open Access: This is an open-access anticle distributed under the 4.0 of

\begin{abstract}
BACKGROUND: The coronavirus disease (COVID-19) pandemic has been a global challenge since its first encounter. It has changed the daily lives of families including the sexual behavior of couples due to public health concerns and government policy to restrict people's movement. It has changed both interpersonal and partne relationships; the time availability at home, the continued presence of children at home, the fear of infection, and the inability to physically interact with others have changed most people's sexual behavior.
\end{abstract}

AIM: This study aims to evaluate sexual behavior changes in marriage people of Indonesia during the COVID-19 pandemic.

METHODS: A cross-sectional online study was conducted, using self-constructed questionnaires. The convenience sample was collected from married males and females for at least 10 months from November 2020 to January 2021. The participants were asked 19 and 20 questions for female and male, respectively, which was an adaptation of the previous questionnaires. Furthermore, a study was conducted to analyze descriptively the changes of sexuality among married people before and during the COVID-19 pandemic.

RESULTS: About 201 participants who completed the survey, 110 males $(54.7 \%)$ and 91 females $(45.3 \%)$ were included in the analyses. The mean age of participants was 37 years old. Most of the participants have middle to high socio-economy classes and have children at home. Shifting in the work schedule is the main reason to change sexual behaviors. Participants experienced significant changes in sexual behaviors and some sexual responses before and during the restriction time.

CONCLUSION: The pandemic has changed sexual behaviors due to social restrictions in Indonesia. These findings imply messages about the consequences of the pandemic on sexual behaviors that may affect the sexual relationship, marriage stability, and physical health itself to fight coronavirus.

\section{Introduction}

Since the emergence of the 2019 novel coronavirus infection in Wuhan, China, it has alarmed people all over the world to its posing a major public health concern and governance challenges. [1]. As of April 18, it has infected more than 140,332,386 people, causing 3,004,088 death cases across all-region [2]. In Indonesia, a total of 1,636,792 confirmed cases of coronavirus disease (COVID)-19 and 44,500 deaths have been recorded to date [3]. These alarming situations have triggered emergency preparedness efforts and public awareness that needs a balanced and prompt approach to inform the public on preventive measurement without causing mental health burden [4]. Moreover, the pandemic will negatively affect sexual behaviors due to health concerns and contact restrictions orders.

A previous study affirmed human sexuality (sexual life and sexual activity) is associated with physical and mental health. Most men and women desire to have positive sexuality throughout their life as an important component of emotional and physical intimacy to maintain sexual health and relationship. [5], [6]. The frequency of partnered sex is a principle mechanism to build a sexual relationship that produces physical health outcomes. In contrast, sexual quality largely refers to individuals' subjective review of their sexual relationships, with physical dimensions differentiated from emotional. Thus, relationship satisfaction and stability are determined by the sexual frequency and sexual quality [6], [7].

The sexual response cycle involving physical and emotional changes may vary between individuals. A desire for intimacy motivates people for sexual activity. Increased heart rate, flushed skin, muscle spasms, hardened nipples, erected penis, and lubricated vagina are the differences that help partners to better understand one another's bodies and response, and enhance sexual experience [8]. An erectile dysfunction of the penis could be a sign of problems in organic or 
psychological in man [9], while a decrease in vaginal lubrication is the common symptom of a woman with sexual arousal disorder [10]. The sexual dysfunction will prohibit penetrative intercourse and it is often accompanied by decline in sexual activity and sexual satisfaction [11], [12].

During the COVID-19 pandemic, the obligation to stay at home would make couples have more time together at home. Initially, we thought that the lockdown would increase the number of conceptions exponentially due to the length of time at home, thus increasing a number of sexual interests. However, many couples have reduced sexual intercourse due to the lack of privacy, a decrease in psychological stimuli, and fear of getting infected. The frequency of various sexual activities also decreased significantly for singles [13] and couples in Italy [14], Germany, Switzerland, and Austria [15].

The previous report showed that the COVID-19 related lockdown impact adult mental health that may be caused by depression, anxiety, and stress in tough economic times [14], [16]. Many peoples declined in their sexual life, but they have an increased in trying new sexual activities in pursuit of sex for leisure [14], [15], [17]. Many women cannot adapt quickly to new restrictions during the pandemic, which showed by a decrease in sexual function and quality of life. The high rate of stress and depression impact negatively on the psychological of a woman despite living together with partners [18]. Despite to date, there is no evidence that COVID-19 could sexually transmit [19], there still a concern about getting infected due to sexual behavior with an asymptomatic partner [20].

The government of Indonesia has not ordered lockdown, instead, they enforced large-scale social restrictions to slow the spread and flatten the curve of COVID-19 on several provinces since April 2020 [21]. In this report, we evaluate the alteration of sexual behaviors in married males and females of Indonesia during the COVID-19 pandemic.

\section{Methods}

\section{Study design}

A cross-sectional online survey was conducted in this study. Self-constructed questionnaires had 19 and 20 questions for female and male, respectively, that included questions assessing participants' demographics and changes in sexual behaviors during the COVID-19 pandemic. Data collection occurred between November 2020 and January 2021 in a convenience sample.

\section{Participants}

Adult participants in Indonesia received links and participate in an anonymous online survey about socio-demographic and sexual behavior. The key demographic variable in our analyses was marital status to assess couple's sexual behavior. Married males or females for at least 10 months were included in this study. We excluded participants who live separately from their partners before the pandemic and divorced couples. Incomplete answers on the questionnaire were ruled out from the analysis. Participants were asked to complete a form that included three sections: Demographic characteristics, the reason for sexual behavior changes, and sexual behavior before and during the COVID-19 pandemic. Questions of questionnaires were formulated based on a study by Cito et al., which consist of sexual behavior and sexual response [14].

All participants provided informed consent about the study, privacy, anonymity, confidentiality, possible risks and benefits, and voluntary involvement by filling out box on the first page of the online survey. Participants were informed that there were no financial incentives to participate. The survey items were pretested on a smaller sample and modified accordingly. The online survey was developed through the use of Google Forms and distributed on social media messaging apps (WhatsApp) and social platforms (Instagram and Facebook). The survey was spread through colleagues, acquaintances, and personal contacts with an indication to send randomly. Data collection was set by limiting the number of possible responses to one per participant.

\section{Data analysis}

The data were analyzed using SPSS version 25.0 (SPSS Inc., USA). The descriptive statistics are shown in number $(n)$ and percentages (\%) for the nominal variables and mean + standard deviation for the variables obtained by measurement. The adequacy of the scale to the normal distribution was investigated using a Kolmogorov-Smirnov test. To assess a difference, Mc Nemar Test and marginal homogeneity test were used to compare changes before and during the pandemic. Values of $p<0.05$ were considered statistically significant.

\section{Ethics}

This study has been approved by the Health Research Ethics Committee Faculty of Medicine Universitas Airlangga (Approval No. 298/EC/KEPK/ FKUA/2020) and recorded informed consent was obtained from each participant before data collection conducted. 


\section{Results}

The survey involved a study population of 222 married male and female in Indonesia whom received link and participate in an anonymous online survey about demographics and sexual behaviors. Of 201 participants who completed the survey, 110 males (54.7\%) and 91 females (45.3\%) were included in the analyses. Participants' demographic characteristics are summarized in Table 1. The mean age of the participants was 37 years for both males and females, respectively. The mean of age the male partner is 34 years and the female partner is 39 years. The majority of participants were middle to high-income classes and they have at least one child at home (80\%). Participants did not experience job changes during the COVID-19 pandemic.

Table 1: Participants' demographic characteristics

\begin{tabular}{lll}
\hline Variable & Male (n) & Female (n) \\
\hline Gender & $110(54.7 \%)$ & $91(45.3 \%)$ \\
Age range, years & $37.3 \pm 10.18$ & $37.1 \pm 11.56$ \\
$15-30$ & $40(36.4 \%)$ & $39(42.9 \%)$ \\
$31-45$ & $50(45.5 \%)$ & $28(30.8 \%)$ \\
$>45$ & $20(18.2 \%)$ & $24(26.4 \%)$ \\
Partner age range, years & $34.6 \pm 9.69$ & $39.1 \pm 12.18$ \\
$15-30$ & $50(45.5 \%)$ & $36(39.6 \%)$ \\
$31-45$ & $43(39.1 \%)$ & $30(33.0 \%)$ \\
$>45$ & $17(15.5 \%)$ & $25(27.5 \%)$ \\
Socioeconomic Status & & \\
Low & $9(8.2 \%)$ & $9(9.9 \%)$ \\
Middle & $43(39.1 \%)$ & $29(31.9 \%)$ \\
High & $58(52.7 \%)$ & $53(58.2 \%)$ \\
No. of a child living in the same home & & \\
0 & $22(20 \%)$ & $19(20.9 \%)$ \\
1 & $40(36.4 \%)$ & $28(30.7 \%)$ \\
2 & $37(33.6 \%)$ & $37(40.7 \%)$ \\
3 & $9(8.2 \%)$ & $6(6.6 \%)$ \\
4 & $1(0.9 \%)$ & $1(1.1 \%)$ \\
$>4$ & $1(0.9 \%)$ & $0(0.0 \%)$ \\
Job change during pandemic & & \\
Yes & $46(41.8 \%)$ & $40(44.0 \%)$ \\
No & $64(58.2 \%)$ & $51(56.0 \%)$ \\
\hline
\end{tabular}

According to our study, four main reasons for participants' sexual behavior changes are shifting in work schedule, work from home, stress, and fearing of COVID-19 infection as presented in Table 2.

Table 2: Reasons for sexual behavior changes

\begin{tabular}{lll}
\hline Question & Male $(\mathrm{n})$ & Female $(\mathrm{n})$ \\
\hline Work schedule & $31(28.2 \%)$ & $29(31.9 \%)$ \\
More time in home & $23(20.9 \%)$ & $20(21.9 \%)$ \\
Fake news about COVID-19 & $1(0.9 \%)$ & $0(0.0 \%)$ \\
Stress & $20(18.2 \%)$ & $9(9.9 \%)$ \\
Fear of getting infected COVID-19 & $18(16.4 \%)$ & $18(19.8 \%)$ \\
Live separately during the pandemic & $3(2.7 \%)$ & $0(0.0 \%)$ \\
Exhausted & $3(2.7 \%)$ & $0(0.0 \%)$ \\
Family problems & $3(2.7 \%)$ & $1(1.1 \%)$ \\
No change & $5(4.6 \%)$ & $9(9.9 \%)$ \\
Others & $3(2.7 \%)$ & $5(5.5 \%)$ \\
\hline CoVID: Coronavirus disease. & &
\end{tabular}

This study showed that participants experienced significant changes in sexual intercourse frequency; desire to have children, contraception use, hygiene before sexual activity, masturbation frequency, frequent time to sexual intercourse, sexual arousal, and sexual satisfaction before and during the COVID-19 era. The statistical differences between before and during pandemic are shown in Table 3.

Our data showed that $43.2 \%$ of participants reported declined sexual frequency to $1 /$ week during
Table 3: Sexual behavior changes

\begin{tabular}{|c|c|c|c|}
\hline Question & $\begin{array}{l}\text { Before COVID-19 } \\
\text { pandemic }(\%)\end{array}$ & $\begin{array}{l}\text { During COVID-19 } \\
\text { pandemic }(\%)\end{array}$ & $p$-value \\
\hline Sexual intercourse frequency per week? & & & 0.000 \\
\hline 0 & $9(4.5)$ & $13(6.5)$ & \\
\hline 1 & $58(28.9)$ & $87(43.3)$ & \\
\hline 2 & $65(32.3)$ & $56(27.9)$ & \\
\hline 3 & $44(21.9)$ & $23(11.4)$ & \\
\hline 4 & $16(7.9)$ & $13(6.4)$ & \\
\hline$>4$ & $9(4.5)$ & $9(4.5)$ & \\
\hline Desire to have children & & & 0.000 \\
\hline Yes & $100(49.8)$ & $80(39.8)$ & \\
\hline No & $101(50.2)$ & $121(60.2)$ & \\
\hline Contraception use & & & 0.001 \\
\hline Yes & $80(39.8)$ & $94(46.8)$ & \\
\hline No & $121(60.2)$ & $107(53.2)$ & \\
\hline Shower before sexual intercourse & & & 0.000 \\
\hline Never & $28(13.9)$ & $20(10.0)$ & \\
\hline Seldom & $90(44.8)$ & $67(33.3)$ & \\
\hline Often & $38(18.9)$ & $48(23.9)$ & \\
\hline Always & $45(22.4)$ & $66(32.8)$ & \\
\hline Masturbation frequency & & & 0.000 \\
\hline 0 & $129(64.2)$ & $110(54.7)$ & \\
\hline 1 & $45(22.4)$ & 40 (19.9) & \\
\hline 2 & $9(4.5)$ & $24(11.9)$ & \\
\hline 3 & $7(3.5)$ & $13(6.5)$ & \\
\hline 4 & $3(1.5)$ & $4(2.0)$ & \\
\hline$>4$ & $8(3.9)$ & $10(5.0)$ & \\
\hline Oral sex frequency & & & 0.857 \\
\hline 0 & $118(58.7)$ & $133(66.2)$ & \\
\hline 1 & $40(19.9)$ & $24(11.9)$ & \\
\hline 2 & $21(10.4)$ & $18(8.9)$ & \\
\hline 3 & $13(6.5)$ & $12(6.0)$ & \\
\hline 4 & $5(2.5)$ & $7(3.5)$ & \\
\hline$>4$ & $4(2.0)$ & $7(3.5)$ & \\
\hline Frequent time to sexual intercourse & & & 0.003 \\
\hline Morning & $39(19.4)$ & $50(24.9)$ & \\
\hline Afternoon & $5(2.5)$ & $11(5.5)$ & \\
\hline Evening & $5(2.5)$ & $7(3.5)$ & \\
\hline Night & $152(75.6)$ & $133(66.1)$ & \\
\hline Sexual desire emerges & & & 0.312 \\
\hline Never & $3(1.5)$ & $5(2.5)$ & \\
\hline Seldom & $76(37.8)$ & $64(31.9)$ & \\
\hline Often & $95(47.3)$ & $103(51.2)$ & \\
\hline Always & 27 (13.4) & $29(14.4)$ & \\
\hline Become sexually aroused & & & 0.027 \\
\hline Never & $1(0.5)$ & $1(0.5)$ & \\
\hline Seldom & $23(11.4)$ & $25(12.4)$ & \\
\hline Often & $78(38.8)$ & $90(44.8)$ & \\
\hline Always & $99(49.3)$ & $85(42.3)$ & \\
\hline Sexual satisfaction & & & 0.000 \\
\hline Not satisfied & $8(4.0)$ & $9(4.5)$ & \\
\hline Slightly satisfied & $22(11.0)$ & $32(15.9)$ & \\
\hline Largely satisfied & $104(51.7)$ & $110(54.7)$ & \\
\hline Very satisfied & $67(33.3)$ & $50(24.9)$ & \\
\hline
\end{tabular}

the pandemic, while $54.2 \%$ of participants were having 2-3 times sexual frequency before the pandemic. More participants $(60.2 \%)$ delay their time to have kids during the pandemic. This number increased $10 \%$ compared to before the pandemic. Preference to use contraception during pandemic increased $17.5 \%$ among participants. The number of participants who often and always get a shower before sexual intercourse increase by $37.3 \%$ during pandemic. The tendency for masturbation activity 2-4×/week was 2 times higher during the pandemic.

Most participants prefer nighttime to have sexual intercourse but the number reduced by $9.5 \%$ during the pandemic. They shift their sexual intercourse time more in the morning and afternoon (30.3\%). Besides, participants frequently get sexual arouse and sexual satisfaction before and during pandemics without significant change in response number.

Participants' sexual response cycles are shown in Table 4. The sexual penetration, ejaculation, and sexual duration in males were comparable before and during the pandemic. Similarly, there was no difference in females' sexual response in the case of orgasm, and 
Table 4: Sexual response cycle in males and females

\begin{tabular}{|c|c|c|c|}
\hline Question & $\begin{array}{l}\text { Before COVID-19 } \\
\text { pandemic }(\%)\end{array}$ & $\begin{array}{l}\text { During COVID-19 } \\
\text { pandemic }(\%)\end{array}$ & p-value \\
\hline \multicolumn{4}{|l|}{ Male } \\
\hline Erection hardness score & & & 0.002 \\
\hline 1 & $1(0.9)$ & $3(2.7)$ & \\
\hline 2 & $10(9.1)$ & $10(9.1)$ & \\
\hline 3 & $21(19.1)$ & $26(23.6)$ & \\
\hline 4 & 78 (70.9) & 71 (64.6) & \\
\hline Penetration occurs & & & 0.841 \\
\hline Never & $0(0.0)$ & $1(0.9)$ & \\
\hline Seldom & $7(6.4)$ & $7(6.4)$ & \\
\hline Often & $39(35.4)$ & $35(31.8)$ & \\
\hline Always & $64(58.2)$ & 67 (60.9) & \\
\hline Ejaculation occurs & & & 0.670 \\
\hline Never & $0(0.0)$ & $1(0.9)$ & \\
\hline Seldom & $6(5.5)$ & $6(5.5)$ & \\
\hline Often & $23(20.9)$ & $22(20)$ & \\
\hline Always & $81(73.6)$ & $81(73.6)$ & \\
\hline Sexual duration problems & & & 0.219 \\
\hline Yes & 39 (35.5) & $43(39.1)$ & \\
\hline No & $71(64.5)$ & $67(60.9)$ & \\
\hline \multicolumn{4}{|l|}{ Female } \\
\hline Vaginal lubrication & & & 0.006 \\
\hline Never & $1(1.1)$ & $1(1.1)$ & \\
\hline Seldom & $11(12.1)$ & $16(17.6)$ & \\
\hline Often & $36(39.5)$ & $40(44.0)$ & \\
\hline Always & $43(47.3)$ & $34(37.3)$ & \\
\hline Reaching orgasm & & & 0.117 \\
\hline Never & $4(4.4)$ & $3(3.3)$ & \\
\hline Seldom & $25(27.4)$ & $24(26.4)$ & \\
\hline Often & $36(39.6)$ & 49 (53.8) & \\
\hline Always & $26(28.6)$ & 15 (16.5) & \\
\hline Pain during sexual intercourse & & & 1.000 \\
\hline Never & 29 (31.9) & $27(29.7)$ & \\
\hline Seldom & $56(61.5)$ & $58(63.7)$ & \\
\hline Often & $4(4.4)$ & $6(6.6)$ & \\
\hline Always & $2(2.2)$ & $0(0.0)$ & \\
\hline
\end{tabular}

pain during sexual intercourse. However, the erection hardness score and vaginal lubrication were significant differences before and during the pandemic.

\section{Discussion}

In this study, we report significant sexual behavior changes in both married males and females before and during the COVID-19 pandemic. The finding of this study consistent with a previous study in Italy [14], [17], [18]. Our study showed, despite having much time together for physical intimacy, our respondents have a lower frequency of sexual intercourse and desire to have children during the pandemic. Undoubtedly, these times have created uncertainty about the future and people must prepare for the multiple scenarios.

Earlier debates in the community dealt with increasing sexual activity and creating a new baby boom on the $1^{\text {st }}$ day of restriction orders. Eventually, keeping a safety over pleasure will be the immediate effects of restriction rules in lowering sexual activity [19]. Understandably, that people experience increased anxiety and stress levels during social restriction [22]. The force to live side by side for $24 \mathrm{~h}$ has made limitation one's own space and it exacerbated existing conflicts within the cohabiting couple, thus weakening the couple bond. Other related pressure such as economic and job instability contributed to such mental burdens that affect sexual function [23].
The other associated factors affecting the alteration of sexual intercourse frequency vary between men and women. The previous report suggested age was no longer predictive for sexual satisfaction in men. Decreasing intercourse frequency in men was associated with longer partnership duration, erectile dysfunction, and inability to achieve orgasm [24]. In contrast, age, parity, duration of relationship, pregnancy, fertility intentions, and contraception were the factors associated with the frequency of sexual intercourse in women [25]. Although men reported experiencing sexual desire 4 times more often than women [26], acute anxiety and uncertainty added to the grief for many losses and maybe an erotic killer, and resulted in more depression and less sex [19].

Although, there is no evidence that coronavirus can be found in vaginal fluid, amniotic fluid, or maternal milk [19], our data showed that the increasing need for contraceptive use and the decreasing time to have kids during a pandemic may be related to the awareness against COVID-19 and pregnancy. In contrast, a study in China reported alteration in condom use among risky sexual participants was due to a great deal of psychological stress during the particular time [13]. Understandably, that parent of newborns decided to delay pregnancy since COVID-19 can cause fetal distress and preterm delivery [19].

Pandemic has brought about drastic changes in work schedule, habits, and activities during home confinement, including bathing and showering time. This phenomenon was revealed in our findings that the number of participants to get a shower before sexual intercourse increased to stay safe and pleasant while getting intimacy.

Our data demonstrated higher masturbatory frequency during the pandemic. The amount of spare time, lack of intimacy, and stress might have led to a rise in solitary sexual activity [19], [20]. The finding was in agreement with a recent report that suggests adding solo and mutual masturbation to adapt to new sexual lives [17].

Shifting in the work schedule and daily routines from home has made couples more freedom to manage time during the pandemic. Most people stayed up later because they did not need to go to work and slept in a little longer [19]. Therefore, our data indicate even participants prefer to have intercourse during nighttime; they tend to shift sexual intercourse to morning and afternoon.

Our study found a comparable reduction in sexual function and sexual arousal in the form of erection hardness and lubricated vagina. The appearance of sexual dysfunction and pleasant sexual response might be caused by fear, guilt, and anxiety as part of the limiting emotions in men and women [19].

Finally, the whole of these findings suggests the necessity of providing an early assessment of sexual 
dysfunction during social restriction measures to provide early treatment for anxiety, as well as, acute stress and depression [23]. Any sexual dysfunction in couples may endanger marital relationships [27]. Cognitive-Behavioral Therapy for Sexual Dysfunction (CBCST) and medical treatment are needed to manage sexual dysfunction for every couple during a pandemic [24].

The current restriction time in Indonesia and its effect on daily routines have significant implications on sexual and relational health. Increased emotional distress, anxiety, and uncertainty have the potential to complicate existing problems related to sexual function and address a new sexual challenge to individuals and couples. There are several limitations to our study that should be noted. The use of unvalidated questionnaires and retrospective data acquisition of sexual behavior alteration was a weakness of the study. Race and ethnic groups appear to have a significant association with the occurrence of sexual dysfunction. Asmall sample size from a single ethnic group limits us to depict the results of the global Indonesian population. Furthermore, incomplete questionnaires, partnership duration, and pregnancy were not collected; hence, the characteristics of the individual and the impact on the overall data were not analyzed. It will be interesting to evaluate annually whether the changes in sexual behavior modify permanently couples' relationships. We expect the information about sexual health can be delivered, so couples may have a better awareness about their sexual life.

\section{Conclusion}

To the best of our knowledge, this is the first study in Indonesia regarding the changes of sexual behavior during COVID-19 in marriage people of Indonesia. These findings imply messages for sexual health experts about the consequences of the pandemic on sexual behaviors that may affect the sexual relationship, marriage stability, and physical health itself to fight coronavirus. Further studies with larger and heterogenous populations and validated questionnaires are needed to depict more findings on sexual behavior changes as affected by pandemic times.

\section{Acknowledgment}

The authors would like to express gratitude to all staff of the Policlinic Andrology, Dr. Soetomo General Hospital Surabaya, especially all participants, colleagues, and acquaintances involved in this study for their help to accomplish this project.

\section{References}

1. Zheng J. SARS-CoV-2: An emerging coronavirus that causes a global threat. Int J Biol Sci. 2020;16(10):1678-85. https://doi. org/10.7150/ijbs.45053

PMid:32226285

2. World Health Organization. COVID-19 Weekly Epidemiological Update. Geneva: World Health Organization; 2021. Available from: https://www.who.int/publications/m/item/weekly-epidemiologicalupdate-on-covid-19---20-april-2021. [Last accessed on 2021 Apr 26].

3. World Health Organization. WHO Coronavirus Disease (COVID-19) Indonesia Situation Reports. Geneva: World Health Organization; 2021. Available from: https://www.covid19.who. int/region/searo/country/id. [Last accessed on $2021 \mathrm{Apr} 26$ ].

4. Olagoke AA, Olagoke OO, Hughes AM. Exposure to coronavirus news on mainstream media: The role of risk perceptions and depression. Br J Health Psychol. 2020;25(4):865-74. https://doi. org/10.1111/bjhp.12427

PMid:32415914

5. Lindau ST, Gavrilova N. Sex, health, and years of sexually active life gained due to good health: Evidence from two US population-based cross sectional surveys of aging. BMJ. 2010;340:580. https://doi.org/10.1136/bmj.c810

6. Ambler RD, Bieber EJ, Diamond MP. Sexual function in elderly women: A review of current literature. Rev Obstet Gynecol. 2012;5(1):16-27.

PMid:22582123

7. Liu H, Waite LJ, Shen S, Wang DH. Is sex good for your health? A national study on partnered sexuality and cardiovascular risk among older men and women. J Health Soc Behav. 2016;57(3):276-96. https://doi. org/10.1177/0022146516661597

PMid:27601406

8. Masters WH, Johnson VE, Kolodny RC. Masters and Johnson on Sex and Human Loving. Canada: Little Brown and Company; 1988.

9. Yafi FA, Jenkins L, Albersen M, Corona G, Isidori AM, Goldfarb S, et al. Erectile dysfunction. Nat Rev Dis Primers. 2016;2:16003. https://doi.org/10.1038/nrdp.2016.3 PMid:27228004

10. Traish AM, Botchevar E, Kim NN. Biochemical factors modulating female genital sexual arousal physiology. J Sex Med. 2010;7(9):2925-46. https://doi. org/10.1111/j.1743-6109.2010.01903.x

PMid:20626599

11. Carpenter LM, Nathanson CA, Kim YJ. Physical women, emotional men: Gender and sexual satisfaction in midlife. Arch Sex Behav. 2009;38(1):87-107. https://doi.org/10.1007/ s10508-007-9215-y

PMid: 17851747

12. Fisher WA, Meryn S, Sand M, Brandenburg U, Buvat J, Mendive $\mathrm{J}$, et al. Communication about erectile dysfunction among men with ED, partners of men with ED, and physicians: The strike up a conversation study (Part I). J Mens Health Gend. 2005;2(1):64-78. https://doi.org/10.1016/j.jmhg.2005.01.018

13. Li W, Li G, Xin C, Wang Y, Yang $\mathrm{S}$. Challenges in the practice of sexual medicine in the time of COVID-19 in China. J Sex Med. 2020;17(7):1225-8. PMid:32418751

14. Cito G, Micelli E, Cocci A, Polloni G, Russo GI, Coccia ME, et al. The impact of the COVID-19 quarantine on sexual life in Italy. Urology. 2021;147:37-42. https://doi.org/10.1016/j. urology.2020.06.101 


\section{PMid:32888982}

15. Hille Z, Oezdemir UC, Beier KM, Hatzler L. The disruptive impact of the COVID-19 pandemic on sexual behavior of a German-speaking population. Sexologies. 2021;30(1):e23-33. https://doi.org/10.1016/j.sexol.2020.12.013

16. Somma A, Krueger RF, Markon KE, Gialdi G, Colanino M, Ferlito $\mathrm{D}$, et al. A longitudinal study on clinically relevant selfreported depression, anxiety and acute stress features among Italian community-dwelling adults during the COVID-19 related lockdown: Evidence of a predictive role for baseline dysfunctional personality dimensions. J Affect Disord. 2021;282:364-71. https://doi.org/10.1016/j.jad.2020.12.165

PMid:33421864

17. Lehmiller JJ, Garcia JR, Gesselman AN, Mark KP. Less sex, but more sexual diversity: Changes in sexual behavior during the COVID-19 coronavirus pandemic. Leisure Sci. 2020;43(1):295-304. https://doi.org/10.1080/01490400.2020.1774016

18. Schiavi MC, Spina V, Zullo MA, Colagiovanni V, Luffarelli $P$, Rago R, et al. Love in the time of COVID-19: Sexual function and quality of life analysis during the social distancing measures in a group of italian reproductive-age women. J Sex Med. 2020;17(8):1407-13. https://doi.org/10.1016/j.jsxm.2020.06.006 PMid:32653391

19. Ibarra FP, Mehrad M, Mauro M, Godoy MF, Cruz EG, Nilforoushzadeh MA, et al. Impact of the COVID-19 pandemic on the sexual behavior of the population. The vision of the east and the west. Int Braz J Urol. 2020;46(S1):104-12. https://doi. org/10.1590/s1677-5538.ibju.2020.s116 PMid:32550703

20. Pennanen-lire C, Prereira-Lourenço M, Padoa A, Ribeirinho A, Samico A, Gressler M, et al. Sexual health implications of COVID-19 pandemic. Sex Med Rev. 2021;9(1):3-14. https://doi. org/10.1016/j.sxmr.2020.10.004

PMid:33309005
21. Andriani $H$. Effectiveness of large-scale social restrictions (PSBB) toward the new normal era during COVID-19 outbreak: A mini policy review. J Indones Health Pol Admin. 2020;5(2):615. https://doi.org/10.7454/ihpa.v5i2.4001

22. Wang C, Pan R, Wan X, Tan Y, Xu L, Ho CS, et al. Immediate psychological responses and associated factors during the initial stage of the 2019 Coronavirus disease (COVID-19) epidemic among the general population in China. Int J Environ Res Public Health. 2020;17(5):1729. https://doi.org/10.3390/ ijerph17051729

PMid:32155789

23. Brooks SK, Webster RK, Smith LE, Woodland L, Wessely S, Greenberg N, et al. The psychological impact of quarantine and how to reduce it: Rapid review of the evidence. Lancet. 2020;395(10227):912-20.

PMid:32112714

24. Westerman ME, Maldonado F, Andrews JR, Sharma V, Trost L, Ziegelmann MJ. Intercourse frequency among men presenting to a sexual health clinic: Does age matter? Int J Impot Res. 2021;33(1):49-54. https://doi.org/10.1038/s41443-019-0222-z PMid:31896829

25. Schneidewind-Skibbe A, Hayes RD, Koochaki PE, Meyer J, Dennerstein $L$. The frequency of sexual intercourse reported by women: A review of community-based studies and factors limiting their conclusions. J Sex Med. 2008;5(2):301-35. https:// doi.org/10.1111/j.1743-6109.2007.00685.x PMid: 18086175

26. Regan PC, Atkins L. Sex differences and similarities in frequency and intensity of sexual desire. Soc Behav Personal. 2006;34(1):95-102. https://doi.org/10.2224/sbp.2006.34.1.95

27. Khazaei M, Rostami R, Zaryabi A. The relationship between sexual dysfunctions and marital satisfaction in Iranian married students. Proc Soc Behav Sci. 2011;30:783-5. https://doi. org/10.1016/j.sbspro.2011.10.152 